\title{
Are Primary Care Residents Trained to Perform Skin Cancer Examinations?
}

\author{
Richard A. Shellenberger, $D O^{7}$, Karine Tawagi, $M D^{2}$, Sweta Kakaraparthi, $M D^{3}$, \\ Jeremy Albright, Ph. $D^{4}$, Mohammed Nabhan, $M D^{5}$, and Alan C. Geller, MPH, RN ${ }^{6}$
}

'Internal Medicine Residency Program, St. Joseph Mercy Hospital Ann Arbor, Ypsilanti, MI, USA; ${ }^{2}$ St. Joseph Mercy Hospital Ann Arbor, Ann Arbor, USA; ${ }^{3}$ Brody School of Medicine, Division of Hematology/Oncology, East Carolina University, Greenville, SC, USA; ${ }^{4}$ Methods Consultants of Ann Arbor, Ann Arbor, MI, USA; ${ }^{5}$ Internal Medicine Residency Program, St. Joseph Mercy Hospital, Ann Arbor, USA; ${ }^{6}$ Department of Social and Behavioral Sciences, Harvard School of Public Health and the Director, Melanoma Epidemiology, Department of Dermatology, Massachusetts General Hospital, Boston, MA, USA.

KEY WORDS: cancer screening; medical education—clinical skills training; curriculum/program evaluation; malignant melanoma; public health.

J Gen Intern Med 33(11):1839-41

DOI: $10.1007 / \mathrm{s} 11606-018-4572-\mathrm{x}$

(C) Society of General Internal Medicine 2018

\section{INTRODUCTION}

Skin cancer remains the most common cancer in the United States (US), with incidence of both nonmelanoma skin cancers and malignant melanoma rising. ${ }^{1}$ Visual skin cancer examination (SCE) screening rates remain among the lowest for any detectable cancer. ${ }^{2}$ Lack of training has been identified as a barrier in the performance of SCE. ${ }^{3}$ We evaluated the level of skin cancer education in primary care residency programs with a survey instrument used by Wise et al. in 2009, which showed infrequent training in SCE. ${ }^{4}$ We chose to assess the impact of Wise's study on current residency education and define possible variations in skills and training based on differences in residency programs. Our study evaluated smaller and less urban residency programs since rural areas have lower population densities of dermatologists and higher melanoma mortality rates. ${ }^{5}$

\section{METHODS}

\section{Survey Administration}

We invited 25 Internal Medicine (IM) and 22 Family Medicine (FM) Michigan residency programs deemed smaller and less urban than the four programs used by Wise et al. ${ }^{4}$ Eight programs (5 IM and 3 FM) participated in 2016. The anonymous surveys were given exemption status by the institutional review board at the corresponding author's institution.

\section{Survey Instrument Measure and Analysis}

We refined and adapted the survey employed by Wise, et al. ${ }^{4}$ This survey was chosen due to prior validation and

Published online July 18, 2018 implementation. ${ }^{4}$ Survey items asked residents to rate their current skill level for performing SCE using a Likert-type scale: A-very or somewhat unskilled; B-neither skilled nor unskilled; and C-somewhat or very skilled. A frequency table (Table 1) summarizes the response distributions for each survey question, overall and separately for family medicine and internal medicine residents. Statistically significant differences between family and internal medicine residents were identified using chi-square test or Fisher's exact test. $P$ values were adjusted for multiple comparisons using Holm's method. Unadjusted odds ratios and $95 \%$ confidence intervals from logistic regressions are also reported comparing responses of very or somewhat skilled to the other two possible responses for each survey item (Table 2). All analyses were performed in R 3.4.2.

\section{RESULTS}

We recruited 144 out of 238 IM and FM residents for a participation rate of $60.5 \%$. Table 1 summarizes univariate responses to questions regarding training in dermatology and SCE for FM and IM residents. Notably, FM residents were much more likely to perform SCE as well as ask about mole changes and $\mathrm{ABCDE}$ of melanoma compared to the IM residents. Self- perceived skill in SCE correlated with dermatology education in medical school or residency, supervision from a dermatologist, and observation of SCE in residency. Discussion of both mole changes and $\mathrm{ABCDE}$ of melanoma also correlated with self-perceived SCE skill level. In the logistic regression analysis (Table 2), the strongest predictor for self-reporting somewhat or very skilled performing SCE was having a dermatology elective in medical school or residency.

\section{DISCUSSION}

Training on SCE in US primary care residency programs remains inadequate with minimal improvement since the 
Table 1 Descriptive Statistics by Practice Type

\begin{tabular}{|c|c|c|c|c|c|}
\hline & & $N(\%)$ & & & \\
\hline \multirow{3}{*}{$\begin{array}{l}\text { Variables } \\
\text { Dermatology elective in } \\
\text { medical school or residency }\end{array}$} & & FM & IM & Total & $P$ value \\
\hline & Yes & $12(35.3)$ & 35 (31.8) & 47 (32.6) & \\
\hline & No & $22(64.7)$ & $75(68.2)$ & $97(67.4)$ & \\
\hline \multirow{3}{*}{$\begin{array}{l}\text { Skin cancer examination in } \\
\text { medical school or residency }\end{array}$} & & & & & $>0.999$ \\
\hline & Yes & $21(61.8)$ & $69(62.7)$ & $90(62.5)$ & \\
\hline & No & $13(38.2)$ & $41(37.3)$ & $54(37.5)$ & \\
\hline \multirow{5}{*}{$\begin{array}{l}\text { Hours spent under } \\
\text { supervision of dermatologist }\end{array}$} & & & & & $>0.999$ \\
\hline & None & $20(58.8)$ & $70(63.6)$ & $90(62.5)$ & \\
\hline & $1-3$ & $3(8.8)$ & $9(8.2)$ & $12(8.3)$ & \\
\hline & $4-10$ & $2(5.9)$ & $7(6.4)$ & $9(6.3)$ & \\
\hline & $>10$ & $9(26.4)$ & $24(21.8)$ & $33(22.9)$ & \\
\hline \multirow{5}{*}{$\begin{array}{l}\text { Times during residency } \\
\text { observing skin cancer examination }\end{array}$} & & & & & $>0.999$ \\
\hline & None & $16(47.1)$ & $47(45.6)$ & $63(46.0)$ & \\
\hline & $1-3$ & $11(32.4)$ & $38(36.9)$ & 49 (35.8) & \\
\hline & $4-10$ & $4(11.8)$ & $10(9.7)$ & $14(10.2)$ & \\
\hline & $>10$ & $3(8.8)$ & $8(7.8)$ & $11(8.0)$ & \\
\hline \multirow{5}{*}{$\begin{array}{l}\text { Number of adult patients for } \\
\text { whom SCE was performed } \\
\text { during residency }\end{array}$} & & & & & 0.001 \\
\hline & None & $6(17.6)$ & $59(57.8)$ & $65(47.8)$ & \\
\hline & $1-3$ & $15(44.1)$ & $23(22.5)$ & $38(27.9)$ & \\
\hline & $4-10$ & $5(14.7)$ & $13(12.7)$ & $18(13.2)$ & \\
\hline & $>10$ & $8(23.5)$ & $7(6.9)$ & $15(11.0)$ & \\
\hline \multirow{4}{*}{$\begin{array}{l}\text { Self-assessed level of } \\
\text { performing SCE }\end{array}$} & & & & & $>0.999$ \\
\hline & Very or somewhat unskilled & $12(35.3)$ & $39(38.32)$ & $51(37.5)$ & \\
\hline & Neither skilled or unskilled & $16(47.1)$ & $54(52.9)$ & $70(51.5)$ & \\
\hline & Somewhat or very skilled & $6(17.6)$ & $9(8.8)$ & $15(11.0)$ & \\
\hline \multirow{5}{*}{$\begin{array}{l}\text { Routinely examines } \\
\text { skin in patients }\end{array}$} & & & & & $>0.999$ \\
\hline & Never & $5(14.7)$ & $20(18.5)$ & 25 (17.6) & \\
\hline & Sometimes & $22(64.7)$ & $67(62.0)$ & $89(62.7)$ & \\
\hline & Often & $6(17.6)$ & $17(15.7)$ & $23(16.2)$ & \\
\hline & Always & $1(2.9)$ & $4(3.7)$ & $5(3.5)$ & \\
\hline \multirow{5}{*}{$\begin{array}{l}\text { ABCDE of melanoma } \\
\text { with patients }\end{array}$} & & & & & 0.028 \\
\hline & Never & $8(23.5)$ & $33(30.6)$ & $41(28.9)$ & \\
\hline & Sometimes & $15(44.1)$ & $66(61.1)$ & $81(57.0)$ & \\
\hline & Often & $9(26.5)$ & $5(4.6)$ & $14(9.9)$ & \\
\hline & Always & $2(5.9)$ & $4(3.7)$ & $6(4.2)$ & \\
\hline \multirow{5}{*}{$\begin{array}{l}\text { Includes changes in moles } \\
\text { or skin lesions in the } \\
\text { review of systems }\end{array}$} & & & & & 0.019 \\
\hline & Never & $8(25.0)$ & 37 (33.6) & $45(44.4)$ & \\
\hline & Sometimes & $11(34.4)$ & $61(55.5)$ & $72(50.7)$ & \\
\hline & Often & $8(25.0)$ & $7(6.4)$ & $15(10.6)$ & \\
\hline & Always & $5(15.6)$ & $5(4.5)$ & $10(7.0)$ & \\
\hline \multirow[t]{5}{*}{ PGY year } & & & & & $>0.999$ \\
\hline & I & $16(47.1)$ & $44(43.6)$ & $60(44.4)$ & \\
\hline & II & $11(32.4)$ & $27(26.7)$ & $38(28.1)$ & \\
\hline & III & $7(20.6)$ & $25(24.8)$ & $32(23.7)$ & \\
\hline & IV & $0(0)$ & $5(5.0)$ & $5(3.7)$ & \\
\hline
\end{tabular}

$P$ values from chi-square and Fisher's exact tests adjusted using Holm's method

2009 study performed by Wise, et al. Despite limitations of the small sample size, we identified statistically significant predictors of self-perceived SCE skills and some differences between FM and IM residents. Finding a correlation between dermatology education or supervision and self-perceived skill in SCE provides support for curriculum reform. To our knowledge, the association between self-reported skill level of residents and having a discussion with patients about either mole changes or ABCDE of melanoma has not been reported elsewhere.
The concept of physician education leading to improved melanoma detection has been established. A recent qualityimprovement project showed primary care physicians (PCP) who received a 90-min internet training session, diagnosed $79 \%$ (95\% CI 15-138\%) more melanoma cases, which were also thinner in Breslow depth, compared to the PCP group who did not receive this education. ${ }^{6}$ The success of this program should interest primary care residency program directors in curriculum reform. Differences in FM and IM residents we surveyed should further challenge IM residency 
Table 2 Residents' Self-reported Skill Level for the Skin Cancer Examination Relative to Covariates

\begin{tabular}{ll}
\hline \hline Variable & $\begin{array}{l}\text { OR (95\% } \\
\text { CI) }\end{array}$ \\
\hline Dermatology elective in medical school or residency & 2.67 \\
& $(1.24-6.12)$ \\
Skin cancer examination in medical school or & 1.09 \\
residency & $(0.53-2.23)$ \\
& 1.50 \\
Hours spent under supervision of dermatologist & $(1.12-2.08)$ \\
Times during residency observing skin cancer & 1.44 \\
examination & $(0.97-2.22)$ \\
Routinely examine skin in patients & 1.66 \\
& $(0.97-2.98)$ \\
Number of adult patients given SCE during residency & 1.72 \\
& $(1.18-2.62)$ \\
Discuss ABCDE of melanoma with patients & 1.92 \\
Include changes in moles or skin lesions in review of & $1.15-3.38)$ \\
systems & $(1.1-2.82)$ \\
More likely to ask about moles and examine patient's & 0.68 \\
skin & $(0.15-2.68)$ \\
Level of training & 0.95 \\
& $(0.64-1.41)$ \\
\hline
\end{tabular}

Odds ratios from logistic regressions are reported comparing responses of "Somewhat or Very Skilled" to "Very and Somewhat Unskilled" and "Neither Skilled nor Unskilled" for each survey item. The odds ratios are unadjusted (that is, each odds ratio is calculated without including any covariates in the logistic regression model), as the survey did not collect demographic information

program directors to consider revision. Despite the current US Preventative Services Task Force recommendations, stating the body of evidence is insufficient for screening asymptomatic individuals to reduce melanoma mortality, we highlight the importance of students and residents to become better educated in identifying both patients and skin lesions at high risk for cancer.

Corresponding Author: Richard A. Shellenberger, DO; Internal Medicine Residency ProgramSt. Joseph Mercy Hospital Ann Arbor, Ypsilanti, MI 48197, USA (e-mail: Richard. Shellenberger@stjoeshealth.org).

\section{Compliance with Ethical Standards:}

Conflict of Interest: The authors declare that they do not have a conflict of interest.

\section{REFERENCES}

1. Dermatology AAo. Skin Cancer. https://www.aad.org/media/stats/conditions/skin-cancer Accessed April 23, 2018.

2. Lakhani NA, Saraiya M, Thompson TD, King SC, Guy GP, Jr. Total body skin examination for skin cancer screening among U.S. adults from 2000 to 2010. Preventive medicine. 2014;61:75-80.

3. Oliveria SA, Heneghan MK, Cushman LF, Ughetta EA, Halpern AC Skin cancer screening by dermatologists, family practitioners, and internists: barriers and facilitating factors. Archives of dermatology. 2011; 147 (1):39-44

4. Wise E, Singh D, Moore $\mathbf{M}$, et al. Rates of skin cancer screening and prevention counseling by US medical residents. Archives of dermatology. 2009; 145 (10):1131-1136.

5. Aneja S, Aneja S, Bordeaux JS. Association of increased dermatologist density with lower melanoma mortality. Archives of dermatology. 2012; 148 (2): 174-178.

6. Weinstock MA, Ferris LK, Saul MI, et al. Downstream consequences of melanoma screening in a community practice setting: First results. Cancer. 2016; 122 (20):3152-3156. 